\title{
Phase Stability and Thermal Insulation of YSZ and Erbia-Yttria co-doped Zirconia EB-PVD Thermal Barrier Coating Systems
}

\author{
G. Boissonnet ${ }^{1}$, C. Chalk ${ }^{2}$, J. R. Nicholls ${ }^{2}$, G. Bonnet $^{1}$, F. Pedraza ${ }^{1}$ \\ 1. Laboratoire des Sciences de l'Ingénieur pour l'Environnement, (LaSIE, UMR-CNRS 7356), Université de La Rochelle, \\ Avenue Michel Crépeau, 17042 La Rochelle, cedex 01 - France. \\ 2. Cranfield University, Surface Engineering and Nanotechnology Institute (SENTi), College Rd., Wharley End, Bedford \\ MK43 0AL - United Kingdom.
}

*corresponding author: boissonnet.germain@gmail.com

Keywords: Thermal barrier coatings (TBCs); Electron-beam physical vapour deposition (EB-PVD); Yttria stabilized zirconia (YSZ); Erbia-yttria co-stabilized zirconia (ErYSZ); thermal diffusivity

\begin{abstract}
In order to cope with the ever-increasing operating temperature of aero gas turbines, new thermal barrier coatings are being investigated. Among the different solutions, erbia-yttria co-doped zirconia coatings made by electron-beam physical vapour deposition (EB-PVD) show promising results in terms of thermal insulation enhancement. Annealing of these coatings was performed at $1100^{\circ} \mathrm{C}$ in air in order to investigate their stability in comparison with that of standard $8 \mathrm{wt} \%$ yttria-stabilized zirconia (8YSZ). Their thermal transport properties were measured using the laser-flash technique. The results show that the as-deposited co-doped coatings offered lower heat conduction than the standard ones in the studied temperature range (from room temperature to $1100^{\circ} \mathrm{C}$ ). However, the microstructural and phase transformations of the co-doped coatings after annealing were significantly greater than those of the standard coatings, hence strongly modifying their thermal insulation potential.
\end{abstract}

\section{Introduction}

Thermal barrier coatings (TBCs) are employed in the hottest sections of aero gas turbines in order to allow the increase in operating temperatures for better engine performance and efficiency while enhancing component durability $[1,2]$. While the plasma spray deposition technique is mostly used for the static components of the hottest part of the aircraft engine, electron-beam physical vapour deposition (EBPVD) are employed to perform segmented columnar TBCs that can accommodate the great thermal and mechanical stresses of turbine blades [3]. The conventional material used for these TBCs is zirconia $\left(\mathrm{ZrO}_{2}\right)$ stabilized with 6 to 9 wt. \% yttria $\left(\mathrm{Y}_{2} \mathrm{O}_{3}\right)$ [4]. As a matter of fact, zirconia presents three allotropic forms which shift from one to another upon temperature, i.e. monoclinic $\left(m-\mathrm{ZrO}_{2}\right)$ to tetragonal $\left(t-\mathrm{ZrO}_{2}\right)$ transformation occurs around $1170^{\circ} \mathrm{C}$ while cubic $\left(c-\mathrm{ZrO}_{2}\right)$ appears above $2370^{\circ} \mathrm{C}$ [5]. These 
transformations are characterized by a volume change that can provoke severe cracking of the zirconia material which, due to the high temperature variations in aero-engines, can further lead to the catastrophic degradation of the component, e.g. $m$ - to $t-\mathrm{ZrO}_{2}$ is associated with a $\sim 4$ vol. \% decrease [6]. Thus, zirconia-based coatings are stabilized using tri- or tetravalent cations into a non-transformable tetragonal form $\left(t^{\prime}-\mathrm{ZrO}_{2}\right)$. While $8 \mathrm{wt}$ \% yttria-stabilized zirconia (8YSZ) is the current coating material for TBCs, other alloying elements were investigated [7]. For instance, stabilizing the zirconia with up to 6 mol. \% of erbia $\left(\mathrm{Er}_{2} \mathrm{O}_{3}\right)$, samaria $\left(\mathrm{Sm}_{2} \mathrm{O}_{3}\right)$, or neodymia $\left(\mathrm{Nd}_{2} \mathrm{O}_{3}\right)$ also led to the stable $t^{\prime}-\mathrm{ZrO}_{2}[8,9,10]$. However, $\mathrm{Sm}_{2} \mathrm{O}_{3}-\mathrm{ZrO}_{2}$ and $\mathrm{Nd}_{2} \mathrm{O}_{3}-\mathrm{ZrO}_{2}$ decomposed into the $m$ and $t$ phases after heat treatment while $\mathrm{Er}_{2} \mathrm{O}_{3}-\mathrm{ZrO}_{2}$ kept its $t$ ' form $[8,9,10]$. One shall note however, very few recent works are reported in the open literature on $\mathrm{RE}_{2} \mathrm{O}_{3}$ rare-earth oxide doping of zirconia for TBC purposes. Rather, the current works are focused on other low thermal conductivity oxides, e.g. $\mathrm{RE}_{2} \mathrm{Zr}_{2} \mathrm{O}_{7}$ pyrochlores.

The ever-increasing temperature for better engine performance and efficiency lead to the development of top coatings with increased thermal insulation potential using, for instance, coating materials with lower thermal conductivities [11]. Among the different doping additives that could stabilize zirconia into its non-transformable $t^{\prime}$ form, nickel oxide $(\mathrm{NiO})$, neodymia $\left(\mathrm{Nd}_{2} \mathrm{O}_{3}\right)$, erbia $\left(\mathrm{Er}_{2} \mathrm{O}_{3}\right)$, ytterbia $\left(\mathrm{Yb}_{2} \mathrm{O}_{3}\right)$ and gadolinia $\left(\mathrm{Gd}_{2} \mathrm{O}_{3}\right)$ were shown to lower the thermal conductivity of YSZ ceramic [12]. Likewise, rareearth (RE) elements are known to be effective to mitigate Calcium-Magnesium-Aluminum-Silicates (CMAS) corrosion [13]. This is because RE elements allow the precipitation of stable apatite silicate and fluorite as soon as the dissolution of the TBC material starts, hence stopping the penetration of the molten silicates. Thus, studying their stability for long term exposure at high temperature is of major interest.

Therefore, in this work, the phase stability and thermal insulation potential of yttria and erbia codoped zirconia EB-PVD coatings have been compared to those of the state-of-the-art yttria-stabilized zirconia (8YSZ). Both coatings were synthesized on Ni-based alloys and exposed to high temperature in order to evaluate the impact of the microstructural transformations on the thermal insulation properties.

\section{Experimental}

The EB-PVD coatings were produced at the Surface Engineering and Nanotechnology Institute (SENTi) in Cranfield University (UK) on Inconel 600 substrates $(15.5 \mathrm{Cr}, 8.0 \mathrm{Fe}, 0.5 \mathrm{Mn},<0.5 \mathrm{Cu},<0.5$ $\mathrm{Si}$, wt. \%, bal. Ni). Prior to the deposition of the ceramic, the Inconel 600 plates were cut into $10 \times 10$ $\mathrm{mm}^{2}$ coupons and aluminized via Chemical Vapour Deposition (CVD). Two different rods were used to perform the production of the $8 \mathrm{YSZ}$ coatings $\left(\mathrm{ZrO}_{2}-8\right.$ wt. \% $\left.\mathrm{Y}_{2} \mathrm{O}_{3}\left(4 \mathrm{~mol} \% \mathrm{Y}_{2} \mathrm{O}_{3}\right)\right)$ and the Y/Er codoped ones $\left(\mathrm{ZrO}_{2}-4 \mathrm{~mol} \% \mathrm{Y}_{2} \mathrm{O}_{3}-4\right.$ mol. $\left.\% \mathrm{Er}_{2} \mathrm{O}_{3}\right)$. During the coating deposition process, the substrate temperature was maintained between $1020^{\circ} \mathrm{C}$ and $1030^{\circ} \mathrm{C}$ once the melt of the ceramic rods had 
been established and the coatings were deposited at a rate of $1.6-2.1 \mu \mathrm{m} / \mathrm{min}$. All the samples were coated during a single run using two flat plate holders that can support ten $10 \times 10 \mathrm{~mm}^{2}$ coupons per side. The two flat plates can thus hold up to 40 samples to perform the EB-PVD coating run. However, this means that all the samples were not at the same distance from the source and thus caused a distribution of thickness and difference in the orientation of the columns. Therefore, the coatings showed slight differences in columnar orientation (0-10 $)$ and thicknesses (120-160 $\mu \mathrm{m})$. Several samples were exposed for $500 \mathrm{~h}$ in air at $1100^{\circ} \mathrm{C}$ in a muffle furnace to induce microstructural changes in the ceramic coating as well as oxidation and transformations of the complete system (substrate $+\mathrm{BC}+\mathrm{TC}$ ).

The microstructural changes were investigated from polished cross-sections with a FEI Quanta 200F scanning electron microscope (SEM) coupled to an EDAX detector for local analysis of the composition using energy dispersive spectrometry (EDS). X-ray diffraction (XRD, Bruker AXS D8 Advance) in $\theta-2 \theta$ mode using $\lambda_{\text {Cu }}$ radiation and Raman micro-spectrometry (Jobin Yvon LabRam HR800, $\lambda_{\text {laser }} \sim 632 \mathrm{~nm}$ ) were employed to follow the structural changes of the ceramic coatings on the surface and on the crosssection respectively. The weight fractions of tetragonal, monoclinic and cubic phases were calculated from the peak intensities of slow scans (step size of $0.01^{\circ}$ at a dwell time of $10 \mathrm{~s}$ per step) on the ranges of interest, i.e. $2 \theta=27$ to $32^{\circ}$ for the $(\overline{1} 11)$ and (111) peaks of the monoclinic phase and $2 \theta=72$ to $76^{\circ}$ for the (400) and (004) peaks of the cubic and tetragonal phases. The integrated intensities were calculated after peak deconvolution and profile fitting performed with the Rietveld method using MAUD software.

The laser-flash technique was employed to assess the evolution of the thermal insulation potential of the TBCs. Thermal diffusivity measurements as a function of the temperature (with a $100^{\circ} \mathrm{C}$ step) were performed using a Linseis LFA1600 apparatus. At each temperature step and for each type of coating (five samples per type of coating), multiple laser pulses separated in time were recorded via an InSb infrared detector situated on the side opposite to the laser impact. In the case of as-deposited coating samples, the measurements were carried out a second time as significant sintering occurred along the first measurement. This phenomenon has been previously reported in the literature on similar YSZ TBCs [14]. After the second measurement, the thermal diffusivity was observed to remain stable. The calculations were performed using a 2-layer model - (i) YSZ and (ii) substrate + aluminide layer - to assess the thermal diffusivity of the full thermal barrier coating systems. Thus, the thermal diffusivity of the substrate was measured before and after ageing at $1100^{\circ} \mathrm{C}$ in air for $500 \mathrm{~h}$ and with or without the $\mathrm{Al}$ diffusion coating. Prior to the measurements with the laser flash, the thicknesses of the multilayer samples were accurately determined $\left( \pm 10^{-3} \mathrm{~mm}\right)$ with a digital caliper. The surfaces of the samples were coated with a graphite spray to foster absorption of the laser and heat emissivity. The thicknesses of the coatings to be used in the multilayer calculations were measured from the cross-sectional images. 


\section{Results and Discussion}

\subsection{Microstructure of the coatings}

Fig. 1 presents the microstructures of the different coatings in their as-deposited state and after annealing at $1100^{\circ} \mathrm{C}$ in air. Both the standard $8 \mathrm{YSZ}$ and $\mathrm{Er} / \mathrm{Y}$ co-doped coatings exhibited similar microstructural features. Therefore, only the Er/Y co-doped coating is presented in its as-deposited conditions (Fig. 1a, 1b and 1c). The full TBC displays the typical ceramic top coatings with a feather like morphology attached to a thin $(\sim 0.6 \mu \mathrm{m}) \alpha-\mathrm{Al}_{2} \mathrm{O}_{3}$ grown on a $\beta$-NiAl bond coating layer of about $30 \mu \mathrm{m}$ (Fig. 1a). The bond coat also contains Al-Cr precipitates and residual alumina particles introduced via grit blasting at the interface with the substrate. One can also note that the ceramic layer displays thin lamellar pores trapped in between the "feather arms" of each column (Fig. 1b and 1c). This porous microstructure is reported in the literature to be responsible for the reduction of the heat transport $[15,16]$.
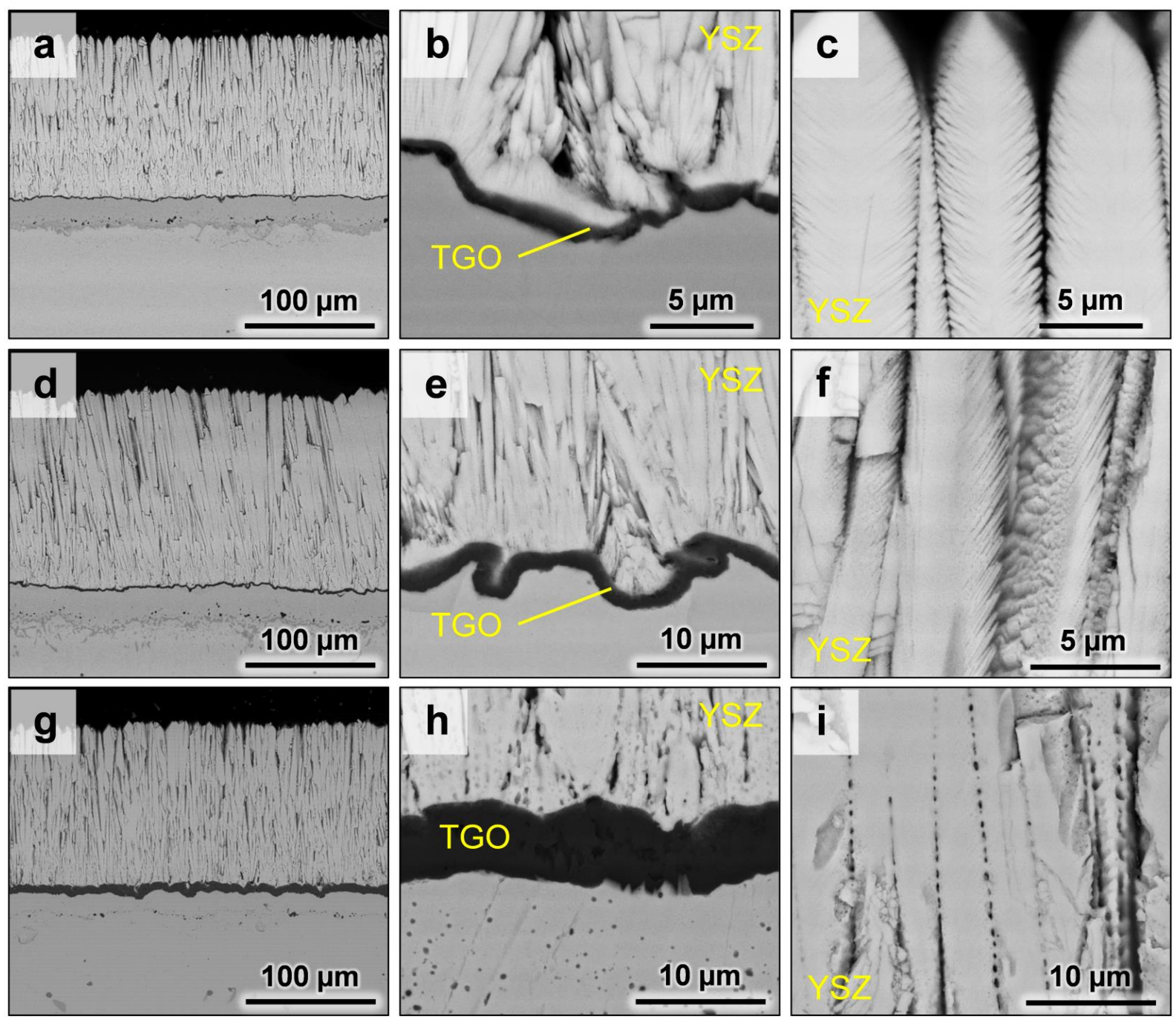

Fig. 1 - SEM micrographs of the EB-PVD coatings in (a, $\boldsymbol{b}$ and $\boldsymbol{c})$ the as-deposited conditions (similar for both standard and co-doped coatings) and after ageing in air at $1100^{\circ} \mathrm{C}$ for $500 \mathrm{~h}$ $(\boldsymbol{d}$, $\boldsymbol{e}$ and $\boldsymbol{f})$ for the standard $8 Y S Z$ coating and $(\boldsymbol{g}, \boldsymbol{h}$ and $\boldsymbol{i})$ the Er/Y co-doped coating. 
After isothermal exposure at $1100^{\circ} \mathrm{C}$ for $500 \mathrm{~h}$, the standard $8 \mathrm{YSZ}$ coated sample exhibits few microstructural transformations of the TBC system (Fig. 1d, 1e and 1f). The additive layer was depleted in $\mathrm{Al}$ and formed $\gamma^{\prime}-\mathrm{Ni}_{3} \mathrm{Al}$ phases within the $\beta$-NiAl layer. The associated bond coating oxidation resulted in the growth of the $\alpha-\mathrm{Al}_{2} \mathrm{O}_{3}$ TGO to a thickness of $\sim 1.2 \mu \mathrm{m}$ (Fig. 1e). Fig. If shows that the intracolumnar gaps started to sinter, closing the thin lamellar pores of the feathery-like columns. However, the sintering of the ceramic appears rather weak as compared with similar coatings aged in analogous conditions $[16,17,18]$. This probably indicates a higher stability of the coatings in this study at the considered temperature. The Raman spectra of Fig. 2 show that the stabilized tetragonal phase of zirconia $\left(\mathrm{t}^{\prime}-\mathrm{ZrO}_{2}\right)$ is the only one detected for both as-deposited and aged coatings, with the characteristic bands of tetragonal $\mathrm{ZrO}_{2}$ at $\sim 150,260,330,470,615$ and $643 \mathrm{~cm}^{-1}$ with the characteristic vibration modes gathered in Table 1 [7,19]. The phase compositions were calculated using Rietveld refinement from the X-ray data in the $72-76^{\circ}$ range (for tetragonal and cubic phases), (Fig. 4a). No significant difference was observed for the 8YSZ standard coating and only tetragonal (t') phase was detected (Fig. 4c), confirming the observations made by Raman spectroscopy.

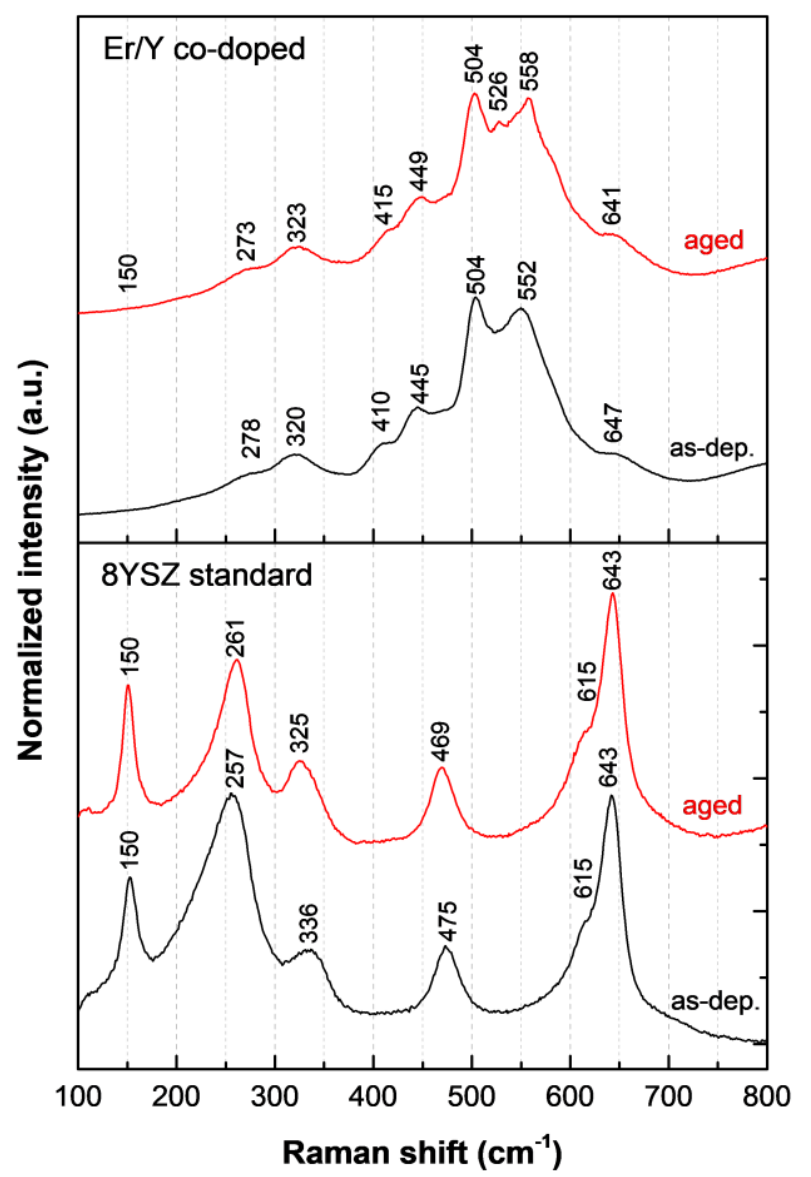

Fig. 2 - Raman spectra of the 8YSZ standard and Er/Y co-doped coatings in their asdeposited conditions and after ageing in air at $1100^{\circ} \mathrm{C}$ for $500 \mathrm{~h}$. 
Table 1 - Raman bands of $8 Y S Z$ and Er/Y co-doped coatings compared with references from the literature and corresponding vibration modes [20-22].

\begin{tabular}{|c|c|c|c|}
\hline $\begin{array}{l}\mathrm{Er} / \mathrm{Y} \text { co-doped } \mathrm{ZrO}_{2} \\
\text { (current work) }\end{array}$ & $\begin{array}{l}\text { 8YSZ standard } \\
\text { (current work) }\end{array}$ & $\begin{array}{l}\boldsymbol{t}-\mathbf{Z r O} \mathbf{2}_{2}\left(\text { Raman shift; } \mathrm{cm}^{-1}\right) \\
\text { [*Naumenko et al.] }\end{array}$ & $\begin{array}{l}\left.\text { Er/YSZ (Raman shift; } \mathrm{cm}^{-1}\right) \\
\text { [ref } 22, * * \text { Patra et al.] }\end{array}$ \\
\hline 150 & 150 & $138-155\left(B_{1 g} / E_{g}\right)$ & \multirow{10}{*}{$\begin{array}{c}\text { between } 200-1100 \\
\text { fluorescence bands: } \\
{ }^{2} \mathrm{H}_{11 / 2} \rightarrow{ }^{4} \mathrm{I}_{15 / 2} \\
{ }^{4} \mathrm{~S}_{3 / 2} \rightarrow{ }^{4} \mathrm{I}_{15 / 2} \\
{ }^{4} \mathrm{~F}_{9 / 2} \rightarrow{ }^{4} \mathrm{I}_{15 / 2}\end{array}$} \\
\hline $273-278$ & $257-261$ & $240-266\left(E_{g} / A_{1 g}\right)$ & \\
\hline $320-323$ & $325-336$ & $290-326\left(B_{1 \mathrm{~g}}\right)$ & \\
\hline $410-415$ & - & $410\left(E_{g}\right)$ & \\
\hline $445-449$ & $469-475$ & $415-474\left(\mathrm{E}_{\mathrm{g}}\right)$ & \\
\hline 504 & - & - & \\
\hline 526 (aged) & - & - & \\
\hline $552-558$ & - & - & \\
\hline- & 615 & $550-616\left(B_{1 g} / E_{g}\right)$ & \\
\hline 647 & 643 & $615-645\left(\mathrm{E}_{\mathrm{g}} / \mathrm{A}_{\mathrm{lg}}\right)$ & \\
\hline
\end{tabular}

In the case of the Er/Y co-doped coating, the sintering and bond coating oxidation is more pronounced (Fig. 1g, 1h and 1i). The contrast of the bond coating layer disappeared almost completely in the BSE micrographs of Fig. 1g, indicating that Al was mostly consumed to form a thick TGO at the interface with the ceramic layer ( $<5 \mathrm{wt} . \% \mathrm{Al}$ via EDS). As a matter of fact, the $\alpha-\mathrm{Al}_{2} \mathrm{O}_{3}$ TGO reached a thickness of $\sim 6 \mu \mathrm{m}$, which is five times the thickness observed for the standard 8YSZ coating aged in the same conditions (Fig. 1h). One shall note that, unlike the standard YSZ coatings, the five aged samples used in the LFA measurements displayed different TGO thicknesses, ranging from 5.2 to $6.5 \mu \mathrm{m}$ (the thicker the ceramic coating, the thinner the TGO scale). Thickening of the alumina scale might be attributed to an increase of the oxidation kinetics of the aluminide triggered by the presence of $\operatorname{Er}_{2} \mathrm{O}_{3}$. For instance, Hou et al. also observed an acceleration of the initial growth kinetics of FeCrAl alloy when coated with RE (Ce, La) oxides [22]. The reactive element oxides (REO) are known to be oxygendeficient oxides and Chevalier et al. proposed that oxygen transport could be accelerated around these particles [23]. By studying the impact of $\mathrm{Nd}_{2} \mathrm{O}_{3}$ and $\mathrm{Y}_{2} \mathrm{O}_{3}$ coatings on top of alumina forming alloys on the oxidation at high temperature $\left(1050^{\circ} \mathrm{C}, 1100^{\circ} \mathrm{C}\right.$ and $\left.1200^{\circ} \mathrm{C}\right)$, they also observed an increase of the mass gain and higher oxidation rates for both types of coatings compared with the uncoated substrate. In addition, different reaction products between the REO and alumina could be formed depending on the oxidation temperature [23]. Although we have not observed such reaction compounds in our system, it appears that the doping effect of Er effectively fosters the growth of the TGO compared to the standard YSZ coating.

The Er/Y ceramic coating exhibits a more sintered microstructure than the standard one as closure of the inter-columnar gaps started via the formation of sintering bridges between the columns (Fig. 1h and 1i). This enhanced sintering could also be explained by the increased affinity of erbium to oxygen with respect Y [23]. Also, the increased anionic diffusion in the presence of Er fosters sintering because the 
latter depends on ionic diffusion. The Raman spectra for the Er/Y co-doped coatings (Fig. 2) show that the same bands are observed for both as-deposited and aged conditions. The bands observed at $\sim 275,320$, 410, 445, 504, 552 and $650 \mathrm{~cm}^{-1}$ have also been observed for Er/Y co-doped zirconia powders in the work of He et al. [24]. These authors explained that the Raman bands of zirconia overlap with the fluorescence bands of $\mathrm{Er}^{3+}$, thus preventing a clear identification of the phases of $\mathrm{ZrO}_{2}$. Nonetheless, some peaks seem to match with some of the Raman bands of the tetragonal phase of zirconia (Table 1). The X-ray diffractograms of Er/Y co-doped coatings agrees with this assumption as they show that the tetragonal $t^{\prime}$ phase of $\mathrm{ZrO}_{2}$ is the main phase of the coatings in the as-deposited and aged conditions (Fig. 3). The phase composition of the Er/Y co-doped coating (Fig. 4c) indicates that the coating also contains cubic $\left(c-\mathrm{ZrO}_{2}\right)$ and a second tetragonal phase $\left(t-\mathrm{ZrO}_{2}\right)$. The existence of a second tetragonal phase was highlighted by several other authors and is related to the lower content of $\mathrm{Y}$ in the tetragonal phase than in the $t^{\prime}-\mathrm{ZrO}_{2}[25,26]$. With annealing at $1100^{\circ} \mathrm{C}$, the $\mathrm{Er} / \mathrm{Y}$ co-doped coating destabilizes. The $t^{\prime}-\mathrm{ZrO}_{2}$ content decreases with annealing at $1100^{\circ} \mathrm{C}$ at the expense of $c-\mathrm{ZrO}_{2}$ and $t-\mathrm{ZrO}_{2}$. This could indicate that diffusion of the stabilizing species (Er and/or Y) occurs during annealing that leave the $t^{\prime}-\mathrm{ZrO}_{2}$ to form the Y-depleted $t-\mathrm{ZrO}_{2}$ and the Y-enriched $c-\mathrm{ZrO}_{2}$. Such diffusion of the species could also explain the high sinterability of the coating.

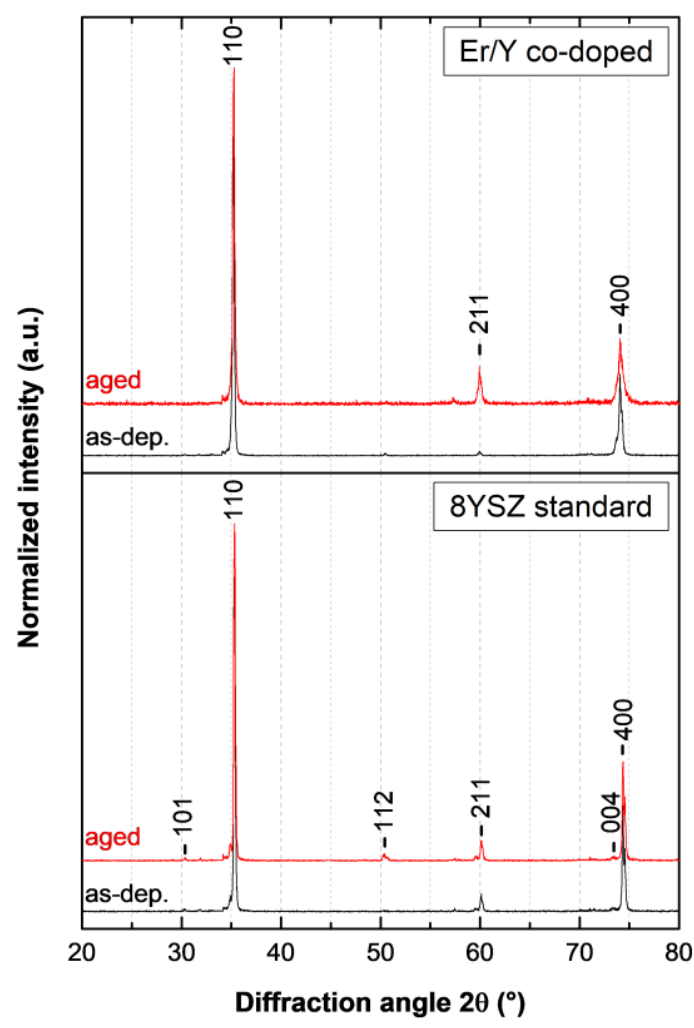

Fig. 3 - X-ray diffractograms of the 8YSZ standard and Er/Y co-doped coatings in their asdeposited conditions and after ageing in air at $1100^{\circ} \mathrm{C}$ for $500 \mathrm{~h}$. 

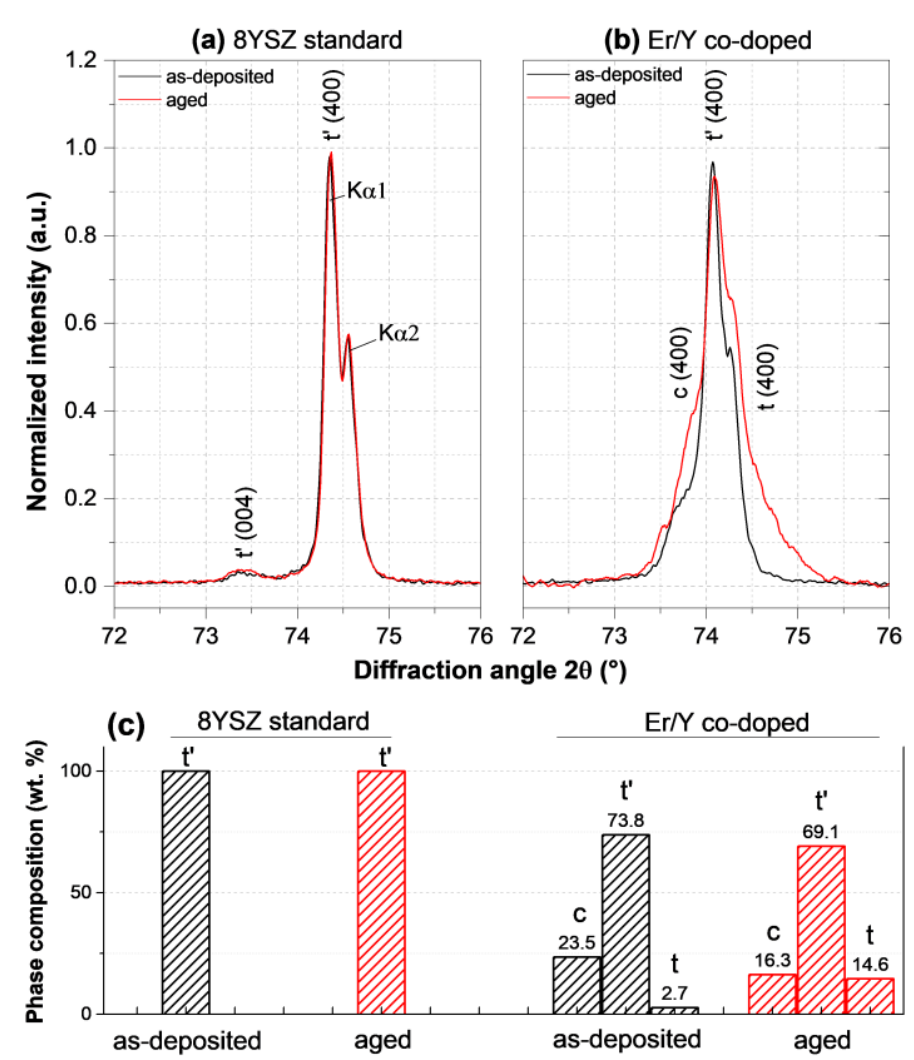

Fig. 4 - X-ray diffractograms of the $72-76^{\circ}$ range for a) $8 Y S Z$ standard and b) Er/Y co-doped coatings in their as-deposited conditions and after ageing in air at $1100^{\circ} \mathrm{C}$ for $500 \mathrm{~h}$ and c) the corresponding phase composition measured using Rietveld refinement.

\subsection{Thermal diffusivity}

The thermal diffusivities as a function of temperature for the 8YSZ standard coatings in their asdeposited state, pre-sintered after the first laser-flash measurement, and after $500 \mathrm{~h}$ of annealing in air are presented in Fig. 5a. The thermal diffusivity follows the same decreasing tendency for the three different states of the coating, followed by an increase above $900^{\circ} \mathrm{C}$. This temperature dependence is typical for zirconia, as phonon-phonon scattering is the dominant mechanism responsible for thermal transport and, is consistent with the experimental results for YSZ described in the literature [27,28]. In the as-deposited state, the 8 YSZ standard coating exhibits a maximum of the thermal diffusivity of $\sim 6.3 \times 10^{-7} \mathrm{~m}^{2} . \mathrm{s}^{-1}$ at room temperature and a minimum of $\sim 3.7 \times 10^{-7} \mathrm{~m}^{2} \cdot \mathrm{s}^{-1}$ at $900^{\circ} \mathrm{C}$. When measured a second time, after the pre-sintering of the first laser-flash measurement, the coatings exhibit approximately the same thermal diffusivity values than the as-deposited ones with only a slight increase after $500^{\circ} \mathrm{C}$. This slight increase might be attributed to the sintering of the smallest pores of the coatings. It has been noticed that the thermal conductivity increase is usually more significant at the beginning of any annealing. Such behavior has been extensively demonstrated in previous studies. For instance, an increase in thermal conductivity was already observed when the as-deposited EB-PVD YSZ coatings were measured on the cooling stage of the laser-flash measurement from $1100^{\circ} \mathrm{C}$ or after only $1 \mathrm{~h}$ at $1100^{\circ} \mathrm{C}[16,17]$. After ageing at $1100^{\circ} \mathrm{C}$ 
in air for $500 \mathrm{~h}$, the thermal diffusivity of the coatings remained barely the same, which is thus in agreement with the observed absence of significant microstructural transformation or phase change. However, the thermal diffusivity values varied from one sample to the other (Fig. 5b). This discrepancy between the different samples is also observed to increase with temperature. This was observed to be related to the variations in thickness of the coatings: the thinner the coating, the lower the thermal diffusivity. However, the thickness of the coatings is used in the multilayer calculations and thus should not significantly contribute to such variations in thermal diffusivity. Alternatively, the performed multilayer calculations did not consider the growth of the $\alpha-\mathrm{Al}_{2} \mathrm{O}_{3}$ TGO. Since alumina presents a thermal conductivity significantly lower than that of the metal substrate, it likely increases the resistance to heat transport with the TGO thickening. The impact of the alumina scale on the thermal diffusivity values would thus be more significant for the thin coatings than for the thick ones. In addition, as the thermal conductivity of the alumina decreases with increasing temperature, its impact would become greater at high temperature, hence enhancing the differences between the samples [29]. Therefore, the thermal diffusivity values might be slightly underestimated in the aged samples.
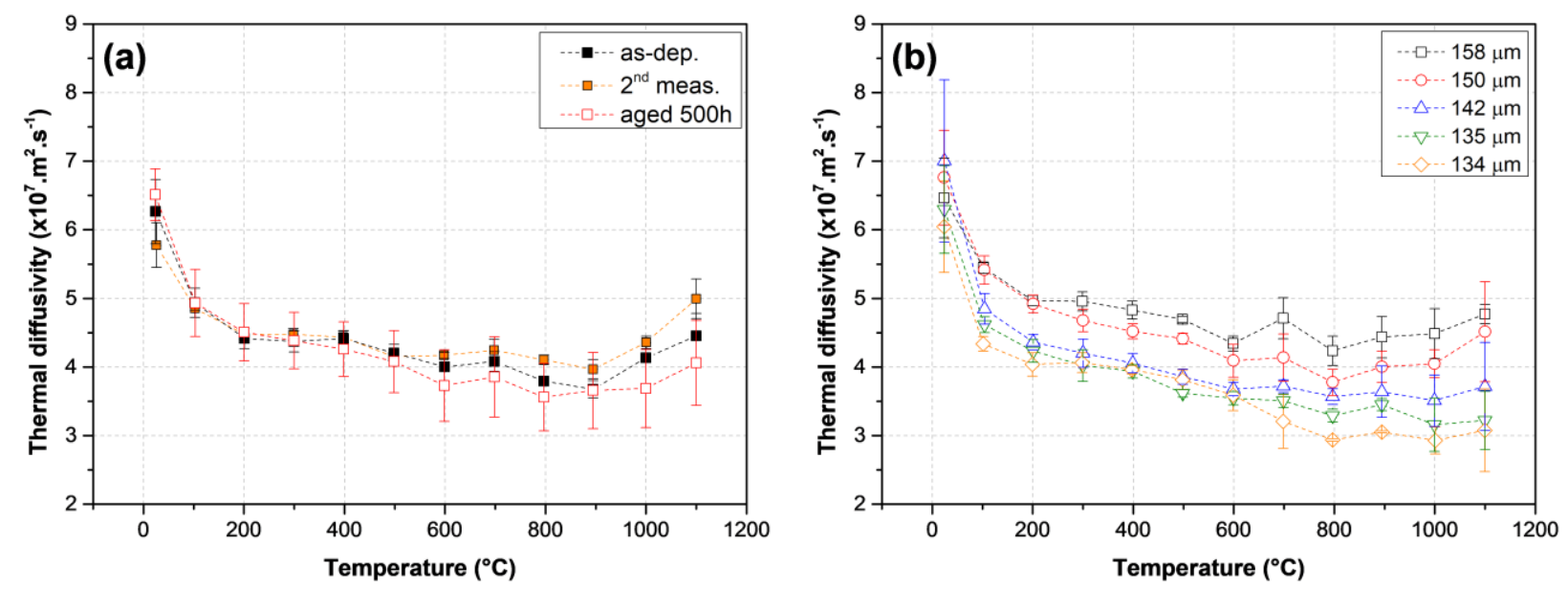

Fig. 5 -a) Thermal diffusivity as a function of the temperature for the 8YSZ standard coatings in the asdeposited conditions, pre-sintered during the first measurement and aged in air at $1100^{\circ} \mathrm{C}$ for $500 \mathrm{~h}$ and b) details of the 5 samples after ageing.

The evolution of thermal diffusivities as a function of temperature is shown in Fig. 6 a for the Er/Y codoped coatings in the three different conditions. The coatings display lower thermal diffusivity in the asdeposited condition than the 8YSZ standard coatings with a maximum of $\sim 4.8 \times 10^{-7} \mathrm{~m}^{2} \cdot \mathrm{s}^{-1}$ at room temperature and a minimum of $\sim 3.5 \times 10^{-7} \mathrm{~m}^{2} \cdot \mathrm{s}^{-1}$ at $600^{\circ} \mathrm{C}$. Therefore, co-doping with $4 \mathrm{~mol} \% \mathrm{Er}_{2} \mathrm{O}_{3}-4$ mol. $\% \mathrm{Y}_{2} \mathrm{O}_{3}$ brings about a $\sim 20 \%$ reduction in the thermal diffusivity compared to the standard 8YSZ composition while a $\sim 30 \%$ reduction was reported when the thermal barrier was doped with 8 mol. \% $\mathrm{Er}_{2} \mathrm{O}_{3}$ [9]. The second measurement of the thermal diffusivity of the same coatings gave higher values ( $\sim 10 \%$ rise) than the as-deposited ones but still lower than those of the conventional 8YSZ. This 
indicates a significant sintering of the coating during the first laser-flash measurement, which did not occur in the $8 \mathrm{YSZ}$ standard coatings. With ageing in air at $1100^{\circ} \mathrm{C}$ for $500 \mathrm{~h}$, the thermal diffusivity of the $\mathrm{Er} / \mathrm{Y}$ co-doped coatings in the low temperature range ( $\mathrm{RT}$ to $500^{\circ} \mathrm{C}$ ) was observed to be higher than the one of the coatings in their initial state. With increasing temperature, the thermal diffusivity remained below the values for the coatings in their initial state. This unusual trend can be attributed to the impact of two opposed factors: (i) the sintering of the coatings that is meant to ease heat conduction, as the number of phonon scattering interfaces is reduced, and (ii) the TGO, that was previously shown to decrease the thermal diffusivity by adding a non-negligible resistance to heat transport (especially at high temperature) [16]. One shall note that the phase transformations are not supposed to take a significant part in the modification of the heat transport compared with the sintering effect. Indeed, previous works that estimated the phase fraction by XRD and the thermal conductivity values as a function of $\mathrm{Y}_{2} \mathrm{O}_{3}$ concentration demonstrated that the phase transformation contributes to less than $10 \%$ to the evolution of the thermal conductivity of ceramic coating $[18,30]$. The sintering was observed to be quite significant in the case of the Er/Y co-doped coatings (Fig. 1i) and thus could explain the rise of the thermal diffusivity in the low temperature range. Several other authors reported a similar increase of the heat conduction when ageing of EB-PVD YSZ coatings at $1100^{\circ} \mathrm{C}[18,16,17]$. Then, as the temperature of the measurement increased, the thermal diffusivity of the coatings decreased due to the increasing heat resistance of the $\alpha-\mathrm{Al}_{2} \mathrm{O}_{3}$ TGO, as previously observed for the aged YSZ standard coatings. The greater reduction of the thermal diffusivity of the Er/Y co-doped aged coatings compared with the one of the standard YSZ aged coatings could be explained by the evolution of the TGO, which is five times thicker in the co-doped systems after ageing. Thus, the underestimation of the thermal diffusivity values for these aged samples could also be even greater than in the case of the aged YSZ standard coatings.

Fig. 6b shows the dispersion of the thermal diffusivity values for the different aged Er/Y co-doped coatings. Clearly, the evolution of the thermal diffusivity was also markedly dependent on the coating thickness. However, as opposed with the aged 8YSZ standard coatings, the dispersion of the values is more pronounced at room temperature. The greater dispersion observed at room temperature could be explained by the fact that the thicknesses of the measured TGO were slightly different between the samples. Also, the microstructural transformations observed for the aged coatings are more significant for these Er/Y co-doped coatings. Therefore, the effect of microstructural transformations and the greater evolution of the TGO thickness could induce a greater dependence of the thermal diffusivity to the coating thickness. 

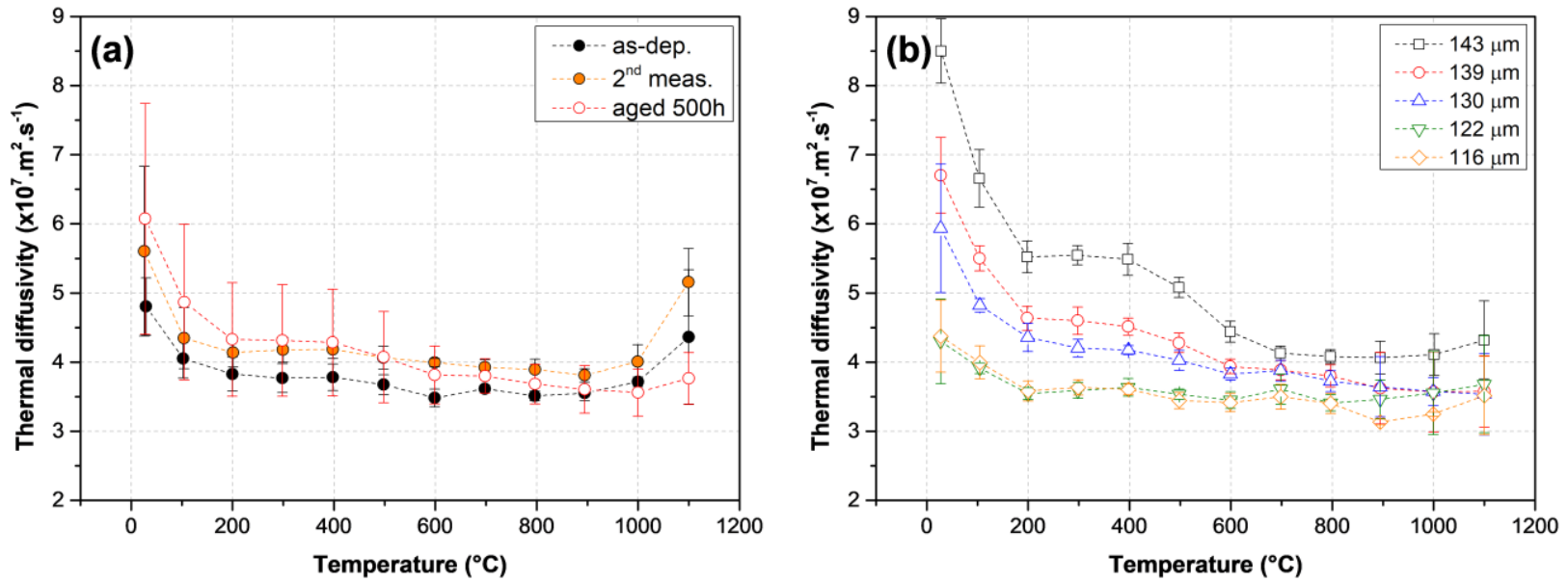

Fig. 6 -a) Thermal diffusivity as a function of the temperature for the 8YSZ standard coatings in the asdeposited conditions, pre-sintered during the first measurement and aged in air at $1100^{\circ} \mathrm{C}$ for $500 \mathrm{~h}$ and b) details of the 5 samples after ageing.

\section{Conclusions}

Erbia-yttria co-doped zirconia coatings made by electron-beam physical vapour deposition (EB-PVD) were compared with the standard 8YSZ coatings. At room temperature, the co-doped coatings showed better thermal insulation than the standard ones. However, after annealing at $1100^{\circ} \mathrm{C}$ in air, the co-doped coating exhibited greater microstructural and phase transformations than its standard counterpart, which led to important thermal insulation changes. Even so, the thermal diffusivity of the Er/Y coating remains below that of the $8 \mathrm{YSZ}$ coating after $500 \mathrm{~h}$ at $1100^{\circ} \mathrm{C}$. However, despite this better thermal insulation potential, the co-doped Er/Y coating was shown to be less stable than the 8YSZ standard coating, leading to a faster degradation of the TBC system. Interaction of the erbia addition with the thermally grown oxide could further lead to a poor lifespan; this could be mitigated by introducing a two-layer TBC microstructure, consisting of a first layer of 8YSZ, overcoated with the low thermal conductivity Er/Y topcoat composition.

\section{ACKNOWLEDGEMENTS}

The authors gratefully acknowledge SR Technics Airfoils Services, Ltd. (Ireland) for providing the samples of this study. G. Boissonnet thanks also the Région Poitou-Charentes for funding his $\mathrm{PhD}$ and the Université de La Rochelle for supporting his stay at Cranfield University. 


\section{REFERENCES}

1. A.G. Evans, D.R. Clarke, C.G. Levi, The influence of oxides on the performance of advanced gas turbines, J. Eur. Ceram. Soc. 28 (2008) 1405-1419.

2. R. Vaßen, M. Ophelia-Jarligo, T. Steinke, D. Emil-Mack, D. Stöver, Overview on advanced thermal barrier coatings, Surf. Coat. Technol. 205 (2010) 938-942.

3. U. Schulz, C. Leyens, K. Fritscher, M. Peters, B. Saruhan-Brings, O. Lavigne, J.M. Dorvaux, M. Poulain, R. Mevrel, M.L. Caliez, Some recent trends in research and technology of advanced thermal barrier coatings, Aerosp. Sci. Technol. 7 (2003) 73-80.

4. D. R. Clarke, M. Oechsner, and N. P. Padture, Thermal-barrier coatings for more efficient gasturbine engines, MRS Bulletin 37 (2012) 891-898.

5. H. Herman and N. R. Shankar, Survivability of thermal barrier coatings. Mater. Sci. Eng. 88 (1987) 69-74.

6. C. Viazzi, J-P. Bonino, F. Ansart, A. Barnabé, Structural study of metastable tetragonal YSZ powders produced via a sol-gel route, Journal of Alloys and Compounds 452 (2008) 377-383.

7. P. A. Langjahr, R. Oberacker, and M. J. Hoffmann, Long-term behavior and application limits of plasma-sprayed zirconia thermal barrier coatings. J. Am. Ceram. Soc., 84 (2001) 1301-1308.

8. K. A. Khor and J. Yang, Lattice parameters, tetragonality (c/a) and transformability of tetragonal zirconia phase in plasma-sprayed $\mathrm{ZrO}_{2}-\mathrm{Er}_{2} \mathrm{O}_{3}$ coatings. Mater. Lett. 31 (1997) 23-27.

9. K. A. Khor and J. Yang, Plasma sprayed $\mathrm{ZrO}_{2}-\mathrm{Sm}_{2} \mathrm{O}_{3}$ coatings: lattice parameters, tetragonality (c/a) and transformability of tetragonal zirconia phase. J. Mater. Sci. Lett. 16 (1997) 1002-1004.

10. K. A. Khor and J. Yang, Transformability of $\mathrm{t}-\mathrm{ZrO}_{2}$ and lattice parameters in plasma sprayed rare-earth oxides stabilized zirconia coatings. Scripta Mater. 37, 9 (1997) 1279-1286.

11. M.R. Winter, D.R. Clarke, Oxide Materials with Low Thermal Conductivity, J. Am. Ceram. Soc. 90 (2007) 533-540.

12. J. R. Nicholls, K. J. Lawson, A. Johnstone and D. S. Rickerby, Methods to reduce the thermal conductivity of EB-PVD TBCs, Surf. Coat. Technol. 151-152 (2002) 383-391.

13. C.G. Levi, J.W. Hutchinson, M-H. Vidal-Sétif and C.A. Johnson, Environmental degradation of thermal barrier coatings by molten deposits, MRS Bulletin 37 (2012) 932-941.

14. H.-J. Rätzer-Scheibe, U. Schulz, The effects of heat treatment and gas atmosphere on the thermal conductivity of APS and EB-PVD PYSZ thermal barrier coatings, Surf. Coat. Technol. 201 (2007) 7880-7888.

15. S. Sampath, U. Schulz, M.O. Jarligo and S. Kuroda, Processing science of advanced thermalbarrier systems, MRS Bulletin 37 (2012) 903-910.

16. A.F. Renteria, B. Saruhan, U. Schulz, H.-J. Raetzer-Scheibe, J. Haug, A. Wiedenmann, Effect of morphology on thermal conductivity of EB-PVD PYSZ TBCs, Surf. Coat. Technol. 201 (2006) 2611-2620.

17. H.-J. Rätzer-Scheibe, U. Schulz, The effects of heat treatment and gas atmosphere on the thermal conductivity of APS and EB-PVD PYSZ thermal barrier coatings, Surf. Coat. Technol. 201 (2007) 7880-7888.

18. A. Azzopardi, R. Mévrel, B. Saint-Ramonda, E. Olson, K. Stiller, Influence of aging on structure and thermal conductivity of Y-PSZ and Y-FSZ EB-PVD coatings, Surf. Coat. Technol. 177-178 (2004) 131-139. 
19. C. M. Ramos, A. S. Tabata, P. F. Cesar, J. H. Rubo, P. A. Silveira Fracisconi, A. F. Sanches Borges, Application of Micro-Raman Spectroscopy to the Study of Yttria-Stabilized Tetragonal Zirconia Polycrystal (Y-TZP) Phase Transformation, Applied Spectroscopy 69 (2015) 810-814.

20. A.P. Naumenko, N.I. Berezovska, M.M. Biliy, O.V. Shevchenko, Vibrational Analysis and Raman Spectra of Tetragonal Zirconia, Physics and Chemistry of Solid State 9 (2008) 121-125.

21. A. Patra, C.S. Friend, R. Kapoor, P.N. Prasad, Upconversion in $\mathrm{Er}^{3+}: \mathrm{ZrO}_{2}$ Nanocrystals, Journal of Physics and Chemistry B 106 (2002) 1909-1912.

22. P. Y. Hou, Z. R. Shui, G. Y. Chuang, and J. Stringer, Effect of Reactive Element Oxide Coatings on the High Temperature Oxidation Behavior of a FeCrAl Alloy, J. Electrochem. Soc. 139 (1992) 1119-1126.

23. S. Chevalier, C. Nivot and J.P. Larpin, Influence of Reactive Element Oxide Coatings on the High Temperature Oxidation Behavior of Alumina-Forming Alloys, Oxidation of Metals 61 (2004) 195217.

24. J. He, M. Luo, L. Jin, M. He, P. Fang, Y. Xie, Raman Spectrum of Er-Y-codoped ZrO 2 and Fluorescence Properties of $\mathrm{Er}^{3+}$, Chinese Journal of Chemical Physics 20 (2006) 90-94.

25. U. Schulz, Phase Transformation in EB-PVD Yttria Partially Stabilized Zirconia Thermal Barrier Coatings during Annealing, J. Am. Ceram. Soc., 83 (2000) 904-910.

26. G. Di Girolamo, C. Blasi, L. Pagnotta, M. Schioppa, Phase evolution and thermophysical properties of plasma sprayed thick zirconia coatings after annealing, Ceramics International 36 (2010) 2273-2280.

27. S. Raghavan, H. Wang, R.B. Dinwiddie, W.D. Porter, and M.J. Mayo, The Effect of Grain Size, Porosity and Yttria Content on the Thermal Conductivity of Nanocrystalline Zirconia, Scripta Mat. 39 (1998) 1119-1125.

28. P.K. Schelling, S.R. Phillpot, Mechanism of Thermal Transport in Zirconia and Yttria-Stabilized Zirconia by Molecular-Dynamics Simulation, J. Am. Ceram. Soc. 84 (2001) 2997-3007.

29. D.G. Cahill, S-M. Lee and T.I. Selinder, Thermal conductivity of $\kappa-\mathrm{Al}_{2} \mathrm{O}_{3}$ and $\alpha-\mathrm{Al}_{2} \mathrm{O}_{3}$ wearresistant coatings, Journal of Applied Physics 83 (1998) 5783-5786.

30. J.-F. Bisson, D. Fournier, M. Poulain, O. Lavigne, R. Mévrel, Thermal conductivity of yttriazirconia single crystals, determined with spatially resolved infrared thermography, J. Am. Ceram. Soc. 83 (2000) 1993-1998. 